\title{
Keloid Scarring: Understanding the Genetic Basis, Advances, and Prospects
}

\author{
Ahmad Sukari Halim ${ }^{1}$, Azadeh Emami ${ }^{1,2}$, Iman Salahshourifar ${ }^{2}$, Thirumulu Ponnuraj Kannan ${ }^{2,3}$ \\ ${ }^{1}$ Reconstructive Sciences Unit, School of Medical Sciences, ${ }^{2}$ Human Genome Center, School of Medical Sciences, ${ }^{3}$ School of Dental Sciences, \\ Universiti Sains Malaysia, Kubang Kerian, Kelantan, Malaysia
}

Keloid disease is a fibroproliferative dermal tumor with an unknown etiology that occurs after a skin injury in genetically susceptible individuals. Increased familial aggregation, a higher prevalence in certain races, parallelism in identical twins, and alteration in gene expression all favor a remarkable genetic contribution to keloid pathology. It seems that the environment triggers the disease in genetically susceptible individuals. Several genes have been implicated in the etiology of keloid disease, but no single gene mutation has thus far been found to be responsible. Therefore, a combination of methods such as association, gene-gene interaction, epigenetics, linkage, gene expression, and protein analysis should be applied to determine keloid etiology.

Keywords Keloid / Skin diseases / Genetics / Environmental exposure

Correspondence: Ahmad Sukari Halim Reconstructive Sciences Unit, School of Medical Sciences, Universiti Sains Malaysia, 16150 Kubang Kerian, Kelantan, Malaysia

Tel: $+609-7676005$

Fax: $+609-7656532$

E-mail: ashalim@kb.usm.my

This study was supported by a Universiti Sains Malaysia (USM) short-term grant (No. 304/PPSP/61310017).

No potential conflict of interest relevant to this article was reported.

Received: 8 Feb 2012 - Revised: 14 Feb 2012 - Accepted: 15 Feb 2012

pISSN: 2234-6163 • elSSN: 2234-6171 • http://dx.doi.org/10.5999/aps.2012.39.3.184 • Arch Plast Surg 2012;39:184-189

\section{INTRODUCTION}

The skin is the largest organ and protects against dangerous environmental factors and water loss. Skin is composed of two main layers: the dermis and the epidermis. The dermis contains a variable amount of fat, collagen, and elastic fibers that provide strength and flexibility to the skin.

Keloids are benign hyperproliferative growths of dermal fibroblasts characterized by the excessive deposition of extracellular matrix components, especially collagen, fibronectin, elastin, proteoglycans, and growth factors such as transforming growth factor (TGF) $\beta[1]$. The mechanisms of keloid formation include alterations in growth factors, collagen turnover, and tension alignment, as well as genetic and immunological contributions. Trauma, foreign-body reactions, infections, and endocrine dysfunctions have all been proposed as risk factors for the development of ke- loids after surgery in genetically susceptible people [1,2]. Keloid disease affects both sexes equally $[3,4]$ and can occur at every age but is more prevalent between the ages of 10 and 30 [5].

\section{EVIDENCE OF A GENETIC BASIS FOR KELOID DISEASE}

\section{Evidence from ethnic groups, families, and twins}

The incidence of keloids is different among populations that reflect different etiologic factors. The worldwide keloid disease prevalence varies according to ethnicity. Patients with darker skin, however, have a higher prevalence than those with lighter pigmentation [6]. It is the fifth most common skin disease in adult black patients in the United Kingdom [3] and the most common skin disease among ethnic Chinese patients in Asia [7]. In addition, many reports have been published on familial 
keloid cases [5,8-11], reflecting the importance of genetic factors among these families. Finally, the high frequency of identical twins both developing keloids also strongly supports a role for genetics in keloid etiology [5,12].

Both autosomal dominant with incomplete penetrance and variable expression modes $[5,9,10]$ as well as autosomal recessive modes of inheritance [13] have been seen among families with keloid disease. Clinical and genetic heterogeneity with a variable clinical expressivity between families and within the affected members of same family has been noted $[5,8-11]$. While the autosomal dominant mode of inheritance with incomplete penetrance is the most common reported model for keloid disease, it remains unclear whether keloid disease is a simple Mendelian or a complex oligogenic disorder. As reviewed more recently, it is well known that environmental factors can trigger the formation of keloids in genetically susceptibility individuals [14]. In addition, studies on people of different ethnicities have discovered non-overlapping associated genes and genomic regions. Taken together, these investigations indicate that a complex inheritance model with contributions from multiple genetic factors along with triggering environmental influences could be the best model for keloid disease. More specifically, it seems plausible that an autosomal gene may play a major role in combination with more moderate recessive gene effects.

\section{Evidence from Mendelian disorders with keloid symp- toms}

Several Mendelian disorders manifest keloids as part of their clinical features. Individuals with a connective-tissue disorder, for example, have a possibility of developing keloids as part of their disease. Almost all Mendelian syndromic forms of keloid disease such as lateral meningocele (OMIM \#130720), Rubinstein-Taybi (OMIM \# 180849), Leigh necrotizing encephalomyelopathy (OMIM \#161700), Ullrich congenital muscular dystrophy (UCMD; OMIM \#254090), Ehlers-Danlos syndrome (OMIM \# 130050), and Goeminne TKCR syndrome (OMIM \#314300) have shown a dominant mode of inheritance that is consistent with the mode of inheritance among families with non-syndromic keloid disease $[5,9,10]$.

Rubinstein-Taybi syndrome 1 (RSTS1) patients develop keloids with high frequency. RSTS1 is caused by a contiguous gene deletion involving the $C R E B B P$ gene as well as other neighboring genes on the chromosome 16p13.3 (OMIM \#180849). A questionnaire-based study of 61 adults with RSTS ranging in age from 18 to 67 years found that $57 \%$ of patients developed keloids [15]. In addition, 28 patients exhibited keloids in a series of 574 examined individuals with RSTS [16]. The high incidence of keloids as both a proliferative disorder and as neoplasms in RSTS patients is attributed to the function of CREBBP in cAMPregulated cell immortalization [17].

Nadeau et al. [18] reported the medical history of 13 patients with UCMD, three of which also had keloids. UCMD is a heterogeneous disease mainly caused by mutations in collagen genes. Similarly, Ehlers-Danlos syndrome (EDS) is an autosomal dominant connective-tissue disorder that manifests keloids as one of the clinical symptoms. EDS type IV is caused by a heterozygous mutation in the gene for type III collagen (COL3A1; 120180) on chromosome $2 \mathrm{q} 31$, close to the gene locus for UCMD syndrome. In addition, overlapping phenotypes have been observed between EDS and UCMD. Finally, Goeminne TKCR syndrome was first reported in a family with six affected members in whom two patients also developed multiple keloids [19].

Therefore, familial aggregation, occurrence in identical twins, Mendelian modes of inheritance, expression studies, and the high prevalence of keloids among different ancestries all provide strong evidence in favor of genetic factors in keloid formation.

\section{GENETIC STUDIES OF KELOID DISEASE}

\section{Evidence from expression studies and gene interaction}

There are 166 studies on PubMed with "gene expression in keloid" as a keyword. With the advent of microarray expression platforms, a long list of genes has been found to be either upregulated or down-regulated in keloid samples. Keloid disease is a complex condition in which multiple interactions between the susceptible genes and their products have been reported. Keloids are enriched in growth factors and extracellular matrix (ECM) molecules, and fibroblasts compose the majority of dermis cells responsible for the production and remodeling of extracellular matrix during wound healing. ECM molecules play an important role in skin structure; therefore, disruption of the ECM could be responsible for abnormal scar tissue formation [20].

As shown in Fig. 1, collagens (type I and III), microfibrillar proteins (elastin, fibrillin) and hyaluronic acid are three major structural elements of the ECM [20]. Of these, collagens act as a network throughout the dermis to maintain tissue integrity and microfibrillar proteins allow flexibility in the deeper dermis [20]. Extensive expression studies focusing on ECM proteins have been carried out. Most expression studies have been conducted on keloid-derived cultured fibroblast cells in comparison with normal tissue. The influence of cell culture components, which are in direct interaction with fibroblast cells, on gene expression is unavoidable. Keloid tissue is characterized by the accumulation of extracellular matrix, especially collagen (Fig. 1). In addition, keloid-derived fibroblast cells exhibit high ex- 
Fig. 1. Extracellular matrix (ECM) in normal skin, and hypertrophic and keloid tissue

ECM components in normal skin compared with hypertrophic scars and keloid tissue. The numbers indicate relative expression. Six means very high expression and -4 indicates very low expression.



pression of TGF $\beta 1$ and TGF $\beta 2[21]$ and consequently oversynthesis of collagen $[22,23]$. TGF $\beta$ stimulates the synthesis of collagen and promotes wound healing via regulating the growth, differentiation, and proliferation of fibroblast cells [24]. TGF $\beta 3$ stimulates collagen synthesis via TGF $\beta 1$ [22] and TGF $\beta 2$ [23]. In addition, the TGF $\beta$ pathway is involved in fibrosis as well as several other fibrotic disorders [14]. It has been shown that in the primary stages of fibrosis in keloid tissues, TGF $\beta 1$ is expressed by neovascular endothelial cells, which consequently stimulates the expression of type I and VI collagens at a high level [25]. TGF $\beta 1$ is a key factor in keloid development and regulates the expression of multiple downstream genes. Exogenous TGF $\beta 1$ upregulates the expression of platelet derived growth factor (PDGF) $\alpha$ receptor in keloid-derived fibroblast cells but not in non-keloid-derived fibroblast cells [26]. It has also been shown that TGF $\beta$ stimulates the expression of vascular endothelial growth factor (VEGF) in keloid fibroblasts as well [27].

$S M A D$ genes act downstream of TGF $\beta$ in keloid development. In keloid fibroblast cells, $S M A D 2$ small interfering RNAs (siRNA) caused the downregulation of SMAD2 and SMAD3, resulting in a decrease in procollagen levels $[28,29]$. This indicates that $S M A D 2$ and $S M A D 3$ play a critical role in TGF $\beta$-induced fibrosis in the formation of keloids.

\section{EVIDENCE FROM LINKAGE AND ASSOCIATION STUDIES}

As mentioned above, familial aggregation studies shed light on the genetic risk factors that might be responsible for keloid formation. Several researchers have since attempted to map the susceptible locus (or loci) of keloid disease in these families.

Genome-wide linkage studies on a Japanese and an African-
American family with keloid disease resulted in the detection of linkage intervals on chromosomal regions $2 \mathrm{q} 23$ and $7 \mathrm{p} 11$, respectively [9]. However, linkage to $7 \mathrm{p} 11$ was excluded from a large Chinese family with keloid disease [30], and linkage intervals at 15q22.31-q23, 18q21.1, and 10q23.31 were found for this family [31,32]. The 18q21.1 region harbors the SMAD 2, 7, and 4 genes, which are involved in regulating of TGF $\beta$ signaling pathway.

Multiple case-control studies have been published on the associations between keloid disease and keloid candidate genes [3340]. Despite strong evidence from expression studies, no study has yet found any association between TGF $\beta$ family members and keloid disease in Caucasian populations [33-36]. However, TGF $\beta 1$ plasma concentration was found to be associated with the $-509 \mathrm{~T}>\mathrm{C}$ variant of TGF $\beta 1$ [41], conflicting with results observed in another study [34].

In addition, downstream genes in the TGF $\beta$ signaling pathway, namely $S M A D$ 3, 6, and 7, did not attain statistical significance in a case-control study examining keloid disease in the Afro-Caribbean ethnicity [42].

In contrast to TGF $\beta$ family members, HLA genes have attained statistical significance in several studies $[37,39,43]$. Of these, HLA-DRB $1 * 15$ appeared to be the most robust with replication in both Chinese and Caucasian ethnic groups [37,39], suggesting that, at least in these ethnic groups, HLA-DRB1*15 might be associated with an increased risk of keloid disease.

\section{GENOME-WIDE STUDIES IN KELOID DISEASE}

With the advent of high-throughput microarray genotyping technologies, researchers have used these methods to look through 
the entire genome. However, there is still no genome-wide linkage study using high-density single-nucleotide polymorphism (SNP) map arrays on families with keloid disease. Recently, however, in a genome-wide case-control association study on a Japanese population, four susceptibility loci for keloid disease were detected including 1q41, 3q22.3-23, and 15q21.3 [44]. A replication study confirmed the possible role of the NEDD4 gene in the 15q21.3 chromosomal region. It has since been shown that NEDD4 upregulates fibronectin and type 1 collagen and so plays a role in the accumulation of extracellular matrix [45]. In another study, copy number variations in 6p21.32, 11q11, 17q12, 8p23.1, 22q13.1, 19p13.1, and 2q14.3 were detected using an array-based comparative genomic hybridization [43]. Region 6p21.32, which harbors HLA-DRB5, also showed a significant association in the validation study.

\section{THE ROLE OF EPIGENETICS IN KELOID DISEASE}

The role of epigenetics in the formation of malignancies is well known. As a keloid is a benign tumor, the possibility of epigenetic alterations in keloid tissue exists. Indeed, it was recently reported that keloid fibroblast cells have altered patterns of DNA methylation and histone acetylation [46]. Examining the methylation profile could give new insight into keloid treatment. However, additional study is needed to fully address the role of epigenetics in the etiology of keloid disease.

\section{CONCLUDING REMARKS AND OUTLOOK}

Keloid disease is a complex condition in which different ethnic groups show different susceptibilities to the development of the disease. The differences in prevalence between populations probably reflect the contributions of different genetic risk factors. In general, most genes in complex disorders have a moderate effect; therefore, association studies, which are powerful methods for detecting genes with moderate effects, are excellent for examining these types of disorders. A range of statistical methods including single marker analysis, genotype analysis, haplotype analysis, relative risk analysis, and gene-gene and gene-environment interaction analyses are also needed to find candidate genes in keloid disease etiology. In addition, a lack of reproducibility among some populations might be the result of small sample size, population stratification, inappropriate statistical analysis methods, or real heterogeneity among populations.

A change in an amino acid alone may not be a sufficient criterion for predicting disease in complex traits such as keloid.
Variants could also exert effects by disrupting or activating the function of splicing binding sites, or hypomorphic variants could exert their effects at the transcription level and interact with other risk factors. However, as no single mutation inside a gene has been detected so far, a multifactorial inheritance model would fit best. Therefore, the interaction between genes and environmental factors, as well as the possible role of coding and regulatory variants and epigenetics must be accounted for in future studies.

\section{REFERENCES}

1. Kelly AP. Medical and surgical therapies for keloids. Dermatol Ther 2004;17:212-8.

2. Kelly AP. Keloids. Dermatol Clin 1988;6:413-24.

3. Child FJ, Fuller LC, Higgins EM, et al. A study of the spectrum of skin disease occurring in a black population in south-east London. Br J Dermatol 1999;141:512-7.

4. Shaffer JJ, Taylor SC, Cook-Bolden F. Keloidal scars: a review with a critical look at therapeutic options. J Am Acad Dermatol 2002;46:S63-97.

5. Marneros AG, Norris JE, Olsen BR, et al. Clinical genetics of familial keloids. Arch Dermatol 2001;137:1429-34.

6. LeFlore IC. Misconceptions regarding elective plastic surgery in the black patient. J Natl Med Assoc 1980;72:947-8.

7. Alhady SM, Sivanantharajah K. Keloids in various races: a review of 175 cases. Plast Reconstr Surg 1969;44:564-6.

8. Bayat A, Arscott G, Ollier WE, et al. "Aggressive keloid": a severe variant of familial keloid scarring. J R Soc Med 2003; 96:554-5.

9. Marneros AG, Norris JE, Watanabe S, et al. Genome scans provide evidence for keloid susceptibility loci on chromosomes 2q23 and 7p11. J Invest Dermatol 2004;122:112632.

10. Chen Y, Gao JH, Liu XJ, et al. Characteristics of occurrence for Han Chinese familial keloids. Burns 2006;32:1052-9.

11. Bella H, Heise M, Yagi KI, et al. A clinical characterization of familial keloid disease in unique African tribes reveals distinct keloid phenotypes. Plast Reconstr Surg 2011;127:689702.

12. Ramakrishnan KM, Thomas KP, Sundararajan CR. Study of 1,000 patients with keloids in South India. Plast Reconstr Surg 1974;53:276-80.

13. Omo-Dare P. Genetic studies on keloid. J Natl Med Assoc 1975;67:428-32.

14. Shih B, Bayat A. Genetics of keloid scarring. Arch Dermatol Res 2010;302:319-39.

15. Stevens CA, Pouncey J, Knowles D. Adults with RubinsteinTaybi syndrome. Am J Med Genet A 2011;155A:1680-4. 
16. Siraganian PA, Rubinstein JH, Miller RW. Keloids and neoplasms in the Rubinstein-Taybi syndrome. Med Pediatr Oncol 1989;17:485-91.

17. Petrij F, Giles RH, Dauwerse HG, et al. Rubinstein-Taybi syndrome caused by mutations in the transcriptional co-activator CBP. Nature 1995;376:348-51.

18. Nadeau A, Kinali M, Main M, et al. Natural history of Ullrich congenital muscular dystrophy. Neurology 2009;73:25-31.

19. Goeminne L. A new probably X-linked inherited syndrome: congenital muscular torticollis, multiple keloids cryptorchidism and renal dysplasia. Acta Genet Med Gemellol (Roma) 1968;17:439-67.

20. Sidgwick GP, Bayat A. Extracellular matrix molecules implicated in hypertrophic and keloid scarring. J Eur Acad Dermatol Venereol 2012;26:141-52.

21. Chalmers RL. The evidence for the role of transforming growth factor-beta in the formation of abnormal scarring. Int Wound J 2011;8:218-23.

22. Murata H, Zhou L, Ochoa S, et al. TGF-beta3 stimulates and regulates collagen synthesis through TGF-beta1-dependent and independent mechanisms. J Invest Dermatol 1997;108: 258-62.

23. Thompson SA, Canady JW, Coberly DM, et al. Effects of TGFbeta2 on collagen synthesis in cultured normal and wounded fetal mouse palates. Cleft Palate Craniofac J 1999; 36:425-33.

24. Bettinger DA, Yager DR, Diegelmann RF, et al. The effect of TGF-beta on keloid fibroblast proliferation and collagen synthesis. Plast Reconstr Surg 1996;98:827-33.

25. Peltonen J, Hsiao LL, Jaakkola S, et al. Activation of collagen gene expression in keloids: co-localization of type I and VI collagen and transforming growth factor-beta 1 mRNA.J Invest Dermatol 1991;97:240-8.

26. Messadi DV, Le A, Berg S, et al. Effect of TGF-beta 1 on PDGF receptors expression in human scar fibroblasts. Front Biosci 1998;3:a16-22.

27. Fujiwara M, Muragaki Y, Ooshima A. Upregulation of transforming growth factor-betal and vascular endothelial growth factor in cultured keloid fibroblasts: relevance to angiogenic activity. Arch Dermatol Res 2005;297:161-9.

28. Gao Z, Wang Z, Shi Y, et al. Modulation of collagen synthesis in keloid fibroblasts by silencing $\operatorname{Smad} 2$ with siRNA. Plast Reconstr Surg 2006;118:1328-37.

29. Wang Z, Gao Z, Shi Y, et al. Inhibition of Smad3 expression decreases collagen synthesis in keloid disease fibroblasts. J Plast Reconstr Aesthet Surg 2007;60:1193-9.

30. Chen Y, Gao JH, Liu XJ, et al. Linkage analysis of keloid susceptibility loci on chromosome $7 \mathrm{p} 11$ in a Chinese pedigree.
Nan Fang Yi Ke Da Xue Xue Bao 2006;26:623-5.

31. Yan X, Gao JH, Chen Y, et al. Preliminary linkage analysis and mapping of keloid susceptibility locus in a Chinese pedigree. Zhonghua Zheng Xing Wai Ke Za Zhi 2007;23: 32-5.

32. Chen Y, Gao JH, Yan X, et al. Location of predisposing gene for one Han Chinese keloid pedigree. Zhonghua Zheng Xing Wai Ke Za Zhi 2007;23:137-40.

33. Bayat A, Bock O, Mrowietz U, et al. Genetic susceptibility to keloid disease and transforming growth factor beta 2 polymorphisms. Br J Plast Surg 2002;55:283-6.

34. Bayat A, Bock O, Mrowietz U, et al. Genetic susceptibility to keloid disease and hypertrophic scarring: transforming growth factor betal common polymorphisms and plasma levels. Plast Reconstr Surg 2003;111:535-43.

35. Bayat A, Bock O, Mrowietz U, et al. Genetic susceptibility to keloid disease: transforming growth factor beta receptor gene polymorphisms are not associated with keloid disease. Exp Dermatol 2004;13:120-4.

36. Bayat A, Walter JM, Bock O, et al. Genetic susceptibility to keloid disease: mutation screening of the TGFbeta 3 gene. BrJ Plast Surg 2005;58:914-21.

37. Lu WS, Zhang WY, Li Y, et al. Association of HLA-DRB1 alleles with keloids in Chinese Han individuals. Tissue Antigens 2010;76:276-81.

38. Zhang G, Jiang J, Luo S, et al. Analyses of CDC2L1 gene mutations in keloid tissue. Clin Exp Dermatol 2012;37:277-83.

39. Brown JJ, Ollier WE, Thomson W, et al. Positive association of HLA-DRB $1 * 15$ with keloid disease in Caucasians. Int J Immunogenet 2008;35:303-7.

40. Yan L, Lu XY, Wang CM, et al. Association between p 53 gene codon 72 polymorphism and keloid in Chinese population. Zhonghua Zheng Xing Wai Ke Za Zhi 2007;23:428-30.

41. Grainger DJ, Heathcote K, Chiano M, et al. Genetic control of the circulating concentration of transforming growth factor type beta1. Hum Mol Genet 1999;8:93-7.

42. Brown JJ, Ollier W, Arscott G, et al. Genetic susceptibility to keloid scarring: SMAD gene SNP frequencies in AfroCaribbeans. Exp Dermatol 2008;17:610-3.

43. Shih B, Bayat A. Comparative genomic hybridisation analysis of keloid tissue in Caucasians suggests possible involvement of HLA-DRB5 in disease pathogenesis. Arch Dermatol Res. 2012;304:241-9.

44. Nakashima M, Chung S, Takahashi A, et al. A genome-wide association study identifies four susceptibility loci for keloid in the Japanese population. Nat Genet 2010;42:768-71.

45. Chung S, Nakashima M, Zembutsu H, et al. Possible involvement of NEDD4 in keloid formation; its critical role in fibro- 
blast proliferation and collagen production. Proc Jpn Acad Ser B Phys Biol Sci 2011;87:563-73.

46. Russell SB, Russell JD, Trupin KM, et al. Epigenetically al- tered wound healing in keloid fibroblasts. J Invest Dermatol 2010;130:2489-96. 